\title{
What Can Drive Consumers' Dining-Out Behavior in China and Korea during the COVID-19 Pandemic?
}

\author{
Yongping Zhong ${ }^{1}$, Segu $\mathrm{Oh}^{2}$ and Hee Cheol Moon ${ }^{1, *}$ \\ 1 Department of International Trade, Chungnam National University, 99 Daehak-ro, Yuseong-gu, \\ Daejeon 34134, Korea; yongping.zhong@hotmail.com \\ 2 School of Business, Chungnam National University, 99 Daehak-ro, Yuseong-gu, Daejeon 34134, Korea; \\ nice69@cnu.ac.kr \\ * Correspondence: hcmoon@cnu.ac.kr
}

Citation: Zhong, Y.; Oh, S.; Moon, H.C. What Can Drive Consumers' Dining-Out Behavior in China and Korea during the COVID-19 Pandemic?. Sustainability 2021, 13, 1724. https://doi.org/10.3390/ su13041724

Academic Editor: Kisang Ryu

Received: 11 January 2021

Accepted: 29 January 2021

Published: 5 February 2021

Publisher's Note: MDPI stays neutral with regard to jurisdictional claims in published maps and institutional affiliations.

Copyright: (c) 2021 by the authors. Licensee MDPI, Basel, Switzerland. This article is an open access article distributed under the terms and conditions of the Creative Commons Attribution (CC BY) license (https:/ / creativecommons.org/licenses/by/ $4.0 /)$.

\begin{abstract}
Currently, living with COVID-19 under certain protective measures still continues as the "new normal" for most of the world. The disruption that the pandemic has caused to societies and economies, especially to the restaurant industry, may last longer than some had thought. This study intended to find out the key drivers of consumers' dining-out intentions and their internal relationships. We adopted the structural equation modeling (SEM) method with 508 surveys collected from China and Korea. The results were as follows: perceived psychological risks, subjective norms, and enjoyment are influential to consumers' dining-out intentions but not restaurant precautionary measures or perceived physical risk; subjective norms have direct implications on both perceived psychological and physical risks, while restaurant precautionary measures can only significantly affect perceived physical risk; enjoyment can be negatively influenced by perceived psychological and physical risks; country can moderate the relationships between subjective norms, perceived physical/psychological risk, and enjoyment. This study provides further understanding of the current food consumption patterns, which will help restaurants set up strategies accordingly to sustain their businesses and get them more prepared for any future outbreaks.
\end{abstract}

Keywords: perceived physical risks; perceived psychological risks; enjoyment; restaurants precautionary measures; restaurant industry; food consumption; COVID-19 pandemic

\section{Introduction}

In the year 2020, humanity is facing an unprecedented global crisis due to the outbreak of COVID-19. Nowadays, the business world is strongly interconnected and can be influenced by various external factors, such as economic, sociocultural, and political variables, including uncontrollable pandemics, but the possible social consequences of the novel coronavirus remain ambiguous [1]. Even through a few countries have developed coronavirus vaccines, problems caused by the pandemic still remain and its negative effects may last longer than some had expected. As there are lots of uncertainties going on, such as mutations of the virus and long-term validity of the vaccines, people may have to prepare for a long-term battle in fighting with the coronavirus. The "new normal" could continue until the vaccine can become available across various countries with a strong evidence showing its validity on maintaining long-term immunity. Therefore, understanding the current new patterns in consumers' food consumption behavior of dining out is still considerably important in order to fulfill consumers' needs and meet their expectations more promptly. Additionally, we believe that this study will still remain significant even after the COVID-19 pandemic is over, since this is not the last pandemic that people are going to face, new infectious diseases probably pop-up three to four times per year across the world [2]. With possibilities of more infectious diseases being reported in societies in the future, it is more urgent than ever for us to fully understand changes of consumer behavior across countries during the pandemic, which will help managers to formulate better strategies to 
deal with any similar situations in the near future and benefit the restaurant industry in the long term.

Currently, as the first, second, and even third waves keep progressing in many countries, the damage caused by COVID-19 may be tremendous. A large number of citizens have negative perceptions towards the prospect of going outside since the pandemic began, and so if people have to visit public places, perceiving high risks of getting infected may lead to huge stress. Negative emotions, including confusion, fear, and anxiety might be common to many people during the pandemic [3]. Xie et al. (2020) [4] pointed out that consumers' choice and consumption of foods can be relatively dynamic, situational, and complicated, largely relying on cultural and social factors and the availability of reliable information regarding the food that they consume. In other words, their decisions regarding food consumption are closely linked to cultural and social factors in their daily lives. Nowadays, consumers' lifestyles are affected significantly by concerns regarding mandated lockdowns, social distancing, and uncertainty brought about by the pandemic [5]. The pandemic has continuously brought huge uncertainty to the restaurant industry because of consumers' reduced demand for food consumption and avoidance of dining out [6]. Moreover, due to differences between countries, such as disease spreading speed, severity, mortality rate, and governmental policy response to COVID-19, consumers from different countries may vary in terms of their attitudes and dining-out intentions.

Countries such as China and South Korea have kept the spread of the virus under control to a certain degree. A new normal life has started in these two countries, where individuals can engage in daily activities outside while obeying some rules to prevent infections of the virus [7-9]. In this study, because China and Korea have been relatively successful in terms of COVID-19 control, and with most of their economic activities returning to normal, we selected China and Korea as our target countries to investigate the determinants of consumers' dining-out intentions in the COVID-19 context.

Even though both China and Korea have a culture of enjoying dining out with others and food sharing [1,10], we believe that under the pandemic, if people perceive high physical/psychological risks of getting infected when they dine out, they are more likely to enjoy it less. In other words, with such risk concerns, consumers may tend to perceive lower levels of enjoyment than they did in the past and even avoid dining out. Consumers also care more about restaurant precautionary measures, like disinfection measures or availability of hand sanitizer, because such measures can relatively reduce the risk of coronavirus infection [11]. Adequate precautionary measures can minimize perceived physical/psychological risks, and motivate consumers to eat out. Meanwhile, subjective norms may also have direct effects on consumers' risk perceptions and their dining-out decisions. According to Hofstede Insights (2020) [12], both Korea and China tend to be collectivism countries, where individuals act in the interests of a group instead of themselves. With a strong collectivist orientation, people are heavily influenced by norms and obligations [13]. Subjective norms, defined as normative expectations from reference groups to perform a particular behavior [14], can play a vital role in shaping Korean and Chinese consumers' consumption behavior. If family members or experts suggest that dining out is not safe, consumers might perceive higher risks on doing so and consequently, reduce their behavioral intentions.

So far, most of the studies have mainly focused on consumers' food consumption behaviors during the lockdown [5,15-17], and many scholars only investigated changes of consumers' traveling behaviors under the pandemic [1,18], but insufficient studies have investigated how people's daily food consumption behavior has been affected after the lockdown or how their behavioral patterns of dining out have been changed under the new normal context. Therefore, in the light of this new context, we intended to examine whether consumers have really adapted to the new normal life, and how their food consumption behaviors have been influenced by factors such as subjective norms, perceived physical and psychological risk, enjoyment, restaurant precautionary measures, and so on. In addition, currently, almost no studies have verified if subjective norms and restaurant 
precautionary measures can effectively impact on consumers' risk perceptions, and if perceived physical/psychological risks can negatively affect consumers' enjoyments of eating out, thus, in order to fill out these research gaps, we decided to test the relationships among them in an explorative way. This study, in turn, may provide more theoretical and practical evidence to contribute to the understanding of changes in consumers' food consumption patterns and also provide some guidelines to enable restaurant industry firms to cope with such changes in order to survive and recover during or after the pandemic. Meanwhile, comparing any possible differences between China and Korea may deepen the understanding of cultural and social factors that influence decisions on food consumption in the pandemic era and enhance the significance of this study. In this study, we tried to solve the following research questions: what are the key drivers of consumers' intention of dining out? How have consumers' food consumption behavior of dining out has been affected by perceived physical/psychological risks, restaurant precautionary measures, subjective norms, and enjoyment under the 'new normal' and what are the correlations among them? Are there any different patterns of consumers' food consumption behaviors between China and Korea?

The remainder of this paper is structured as follows: the second section provides a summary of previous studies and discusses the hypotheses. The third section presents the research methods, which is followed by the fourth section, analysis and results. Finally, the fifth section discusses the theoretical and managerial implications and concludes the limitations with directions for future studies.

\section{Literature Review and Hypotheses}

\subsection{Theory of Reasoned Action (TRA)}

The theory of reasoned action was proposed by Fishbein and Ajzen (1975) [19], which assumed that an individual's behavioral intention is affected by two direct determinants: attitude toward the behavior and subjective norms [20]. In this study, we chose TRA as the fundamental model because it was confirmed to be an important theory that can explain and predict individuals' attitudes, intentions, and behaviors regarding food consumption [14,21-23]. Attitude is closely related to one's positive or negative emotions toward performing a specified behavior, while behavioral intention refers to an individual's intention of performing a particular behavior [19]. However, just like many other studies [24-26], instead of focusing on investigating consumers' attitude, in this study, we concentrated more on their behavioral intentions of dining out and aimed to find out the antecedents of such intentions.

Based on TRA theory, subjective norms are associated with the social pressure that a decision maker perceives in performing a behavior. Rogers (2003) [27] noted that subjective norms can be described as a behavioral pattern that has been established inside a social system. While adopting a specific behavior, subjective norms are related to the positive or negative perceptions gained from external society or a from reference group [28]. Consumers' food consumption behaviors are affected extensively by norms derived from reference groups and the opinions of surrounding people [14], and as part of the social norms, factors such as mass media, expert opinions, and other non interpersonal information were also found to have significant effects on consumers' behavioral intentions [29]. Both in China and Korea, their societies largely depend on collective norms and obligations [1,12], such norms can serve as social standards that shape individuals' behavior in a social system and inform individuals if their behaviors are appropriate or not. If a reference group consider dining out as safe, people could have more positive perceptions on doing so.

Thus, the following hypotheses were proposed:

Hypothesis 1 (H1). Subjective norms positively influence consumers' behavioral intentions towards dining out. 


\subsection{Other Incorporated Factors}

In this study, to better explain consumers' food consumption behaviors of dining out during the pandemic, other significant variables, such as perceived physical and psychological risk, enjoyment, and restaurant precautionary measures, were added to upgrade the theory of reasoned action (TRA) model. Compared to the traditional TRA, with these new variables that can more precisely reflect the current situation, we can explain how consumers' behaviors have been affected under the new normal in a more comprehensive way.

\subsubsection{Perceived Physical/Psychological Risks}

Bauer (1960) [30] first proposed the concept of perceived risk in application to marketing studies to explain consumer behavior. Perceived risk is closely connected to components that can lead to negative outcomes or loss [31]. Reisinger and Mavondo (2005) [32] defined it as consumers' risk perceptions of the uncertainty and negative consequences when purchasing a product or service. In this study, we defined perceived risks as perceived physical and psychological risks.

Perceived physical risks or health risks are considered to equate to consumers' conceptions that if they consume a food, it may cause harm to their body [33]. Novelli et al. (2018) [34] noted that personal and physical concerns for safety can play a key role in consumers' decision making. Perceived physical risks of getting infected with COVID-19 would reduce consumers demand to dine out because they want to avoid exposure to physical threats.

Meanwhile, perceived risk may aggravate anxiety and have a negative effect on behavioral intention [18], which may also lead to perceptions of psychological risks. Human emotions such as fear, guilt, and empathy are critically influential responses to their behaviors, and in terms of food issues, fear caused by uncertainty might be more salient than other emotions $[4,35]$. Thus, negative emotions resulting from perceived psychological risks can reduce consumers' needs to dine out.

In addition, previous research has confirmed the implications of perceived risk for consumers' consumption decisions [3,36,37]. High-risk areas are places that can cause spread of infectious disease due to activities that might increase contact between people, wildlife, and livestock [38]. Restaurants, being public places where lots of people gather together, can increase the possibility of human contact and infection, and cause people's negative perceptions toward dining behaviors. In accordance with Chen et al.'s (2020) [39] research related to the impact of the COVID-19 pandemic on consumption behaviors, they found that offline consumption declined more in cities that reported more COVID-19 cases. In other words, perceived high risks of coronavirus infection physically and mentally may negatively affect consumers' behavioral intentions of dining outside.

As such, the following hypotheses were proposed:

Hypothesis 2 (H2). Perceived physical risks negatively influence consumers' behavioral intentions towards dining out.

Hypothesis 3 (H3). Perceived psychological risks negatively influence consumers' behavioral intentions towards dining out.

However, people's risk perceptions significantly rely on diverse sources to get information, such resources can either be official sources or personal experiences of people around them [40]. Thus, subjective norms associated with opinions from a reference group, like families, friends, and experts, can be influential to consumers' risk perceptions. Because previous studies have provided limited evidence about how subjective norms can affect people's risk perceptions (physical or psychological risk), to further examine the relationships between them, we also tested the connections between subjective norms and perceived physical/psychological risks in this study. We believe that if people in the 
vicinity of a consumer, media, or medical experts deliver the message that dining out is safe, consumers may perceive less risks toward dining out and be more willing to do it. As such, the following hypotheses were proposed:

Hypothesis 4 (H4). Subjective norms can reduce consumers' perceived physical risks towards dining out.

Hypothesis 5 (H5). Subjective norms can reduce consumers' perceived psychological risks towards dining out.

\subsubsection{Restaurant Precautionary Measures}

Restaurants, where cluster infections may occur easily, have raised lots of concerns among people during the pandemic. In the restaurants, if anyone inside got infected with the coronavirus, he/she can ultimately contaminate the environment and anything inside that environment, which consequently, can easily cause person-to-person transmission [41]. Individuals could be exposed to the virus if they touch a contaminated surface or object and consequently get infected via oral, nasal, or optic routes [42].

A close physical contact and food sharing behavior inside restaurants could lead to cluster infections and thus, precautionary practices, such as cleaning the surface of "high touch" areas, providing hand sanitizer, regular hand washing and disinfection measures, of the dining environment can be significant, which may decrease the risks of getting infected [11]. In other words, if a restaurant provides certain precautionary measures like hand sanitizer, contactless payment, separated dining spaces etc., consumers may feel safer, and perceive less physical/psychological risks, which also can lead to favorable intentions of dining inside. Therefore, this study aimed to further verify whether precautionary measures inside the restaurant can impact on people's perceived risks or their dining-out decisions, and provide more empirical evidence.

As such, the following hypotheses were proposed:

Hypothesis 6 (H6). Restaurant precautionary measures positively influence consumers' behavioral intentions towards dining out.

Hypothesis 7 (H7). Restaurant precautionary measures can reduce consumers' perceived physical risks towards dining out.

Hypothesis 8 (H8). Restaurant precautionary measures can reduce consumers' perceived psychological risks towards dining out.

\subsubsection{Enjoyment}

Dining in restaurants provides consumers with functional value by satisfying hunger, providing convenient food, and charging acceptable prices, but at the same time it also creates hedonic value by offering consumers fun, entertainment, or novelty [43]. Such experiential values make a restaurant a nice place where consumers can experience excitement, pleasure, and a sense of happiness [44-46]. Emotions like enjoyment and pleasure could positively impact on consumers' behavior, especially on their purchasing intention [24].

Generally, eating in a restaurant might be linked to an enjoyable and happy experience arising from sharing time with family members and friends [45], which can lead to a positive attitude towards eating out and enhancement of behavioral intentions. Dining behaviors are closely related to social activities, even during the pandemic, if consumers can get some enjoyment from eating out with friends or families, they are more likely to continue such behaviors. Especially, for Korean and Chinese people, they enjoy spending their time with friends or families, and dining out with others $[1,10]$. Meanwhile, based on previous studies, enjoyment was found to be critically important to consumers' behavioral intention $[24,47,48]$. Thus, we believe that enjoyment can be an extremely important factor for consumers to make food consumption decisions in these two countries. 
However, as coronavirus keeps spreading across countries, people may have difficulties to fully enjoy their meals with certain risks of coronavirus infection. Enjoyments gained from dining-out behaviors can be gradually replaced by negative emotions like stress or concerns driven by the fears of getting infected. Perceived (physical/psychological) risks can reduce the joys of eating out and easily discourage consumers' consumptions. However, many studies have linked risks with trust issues in consumption activities [49-51], but insufficient studies have discussed whether perceived (physical/psychological) risks could have negative implications on enjoyments during the purchasing process. In this study, we intended to confirm whether perceived (physical/psychological) risks and enjoyment are correlated.

So, the following hypothesis were proposed:

Hypothesis 9 (H9). Enjoyment positively influence consumers' behavioral intention towards dining out.

Hypothesis 10 (H10). Perceived physical risks negatively influence consumers' enjoyment.

Hypothesis 11 (H11). Perceived psychological risks negatively influence consumers' enjoyment.

\subsection{Country Comparison}

After the outbreak of the COVID-19 pandemic, due to differences in governmental policy response and other social aspects, many countries have different infection rates. In order to reduce the risks of community transmission, governmental public health interventions, such as border controls/closure, quarantine, contact-tracing measures, frequent hand sanitation, social distancing measures, and avoiding mass gatherings, were conducted at different levels across geographical areas [52]. In October, the Chinese government suggested that people took precautions including wearing masks, maintaining safe social distance, washing hands, and avoiding crowded areas and dining together since more citizens may eat out or dine together during national holidays [53], but all of these were not mandatory. During the same month, in Korea, even under eased social distancing conditions, restaurants still had obligations to follow infection prevention measures, including ensuring that visitors wear masks. Furthermore, Korean people were required to wear masks on public transportation and at medical facilities, and violation of such rules would incur a penalty from November [54].

When we did the surveys in October and November, people in both China and Korea were permitted to do most of their daily activities under varying levels of social distancing restrictions. However, considering the countries' differences in infection cases, severity, mortality rate, governmental policy response, and other social aspects, we intended to identify whether there are differences in people's dining-out behavior between these two countries. This study will contribute to the overall understanding of food consumption behaviors under the new normal concept in different countries.

As such, the following hypothesis was proposed:

Hypothesis 12 (H12). There are differences in people's dining-out behaviors between these two countries.

\section{Research Methods}

\subsection{Measures and Sample}

In this study, we tested 5 constructs to investigate the antecedents that may impact upon consumers dining-out behaviors, including subjective norms, perceived physical risks, perceived psychological risks, enjoyment, and restaurant precautionary measures (see Figure 1). Questionnaire items were mostly adapted from previous studies and slightly modified to fit in the context of this study (see Table 1). However, due to a lack of a literature base, items for restaurant precautionary measures were developed by the authors according to the news and public precautionary guidance in both China and Korea. We 
adopted a 5-point Likert scale ranging from " $1=$ strongly disagree" to " $5=$ strongly agree" in this study.

Table 1. Items and factor loading.

\begin{tabular}{|c|c|c|c|c|}
\hline Variables & Items & Factor Loading & Content & Source \\
\hline \multirow{6}{*}{ EJ } & EJ1 & 0.787 & I have fun when I dine out & \multirow{6}{*}[24,45,55]{} \\
\hline & $\mathrm{EJ} 2$ & 0.851 & Dining out provides me with a lot of enjoyment & \\
\hline & EJ3 & 0.818 & I think that dining out is an enjoyable experience & \\
\hline & $\mathrm{EJ} 4$ & 0.803 & Dining out enables me to enjoy the happiness of dining & \\
\hline & EJ5 & 0.717 & I enjoy dining out with my family & \\
\hline & EJ6 & 0.759 & I enjoy dining out with friends & \\
\hline \multirow{5}{*}{ INT } & INT1 & 0.859 & I plan to dine out with my friends in the near future & \multirow{5}{*}[14,56,57]{} \\
\hline & INT2 & 0.850 & I plan to dine out with my family in the near future & \\
\hline & INT3 & 0.881 & I would dine out again & \\
\hline & INT4 & 0.891 & I intend to dine out in the next few weeks & \\
\hline & INT5 & 0.861 & I will very probably dine out in the near future & \\
\hline \multirow{5}{*}{ PHY } & PHY1 & 0.813 & Dining out may not be safe for me & \multirow{5}{*}[56,58]{} \\
\hline & PHY2 & 0.837 & Dining out may damage my health & \\
\hline & PHY3 & 0.668 & Dining out may cause me physical harm & \\
\hline & PHY4 & 0.869 & Dining out may cause me to get infected with COVID-19 & \\
\hline & PHY5 & 0.857 & Dining out exposes me to higher likelihood of COVID-19 infection & \\
\hline \multirow{5}{*}{ PSY } & PSY1 & 0.792 & I feel worried about dining out & \multirow{5}{*}[56,59]{} \\
\hline & PSY2 & 0.860 & I feel uncomfortable about dining out & \\
\hline & PSY3 & 0.896 & I feel anxiety about dining out & \\
\hline & PSY4 & 0.880 & I feel nervous about dining out & \\
\hline & PSY5 & 0.813 & I feel stressful about dining out & \\
\hline \multirow{6}{*}{ RPM } & RPM1 & 0.707 & Restaurants provide separated dining spaces & \multirow{6}{*}{$\begin{array}{c}\text { Self- } \\
\text { developed }\end{array}$} \\
\hline & RPM2 & 0.552 & Restaurants provide liquid soap, hand sanitizer, etc. & \\
\hline & RPM3 & 0.820 & Restaurants provide contactless payment & \\
\hline & RPM4 & 0.843 & Restaurants provide contactless self-checkout or self-order system/service & \\
\hline & RPM5 & 0.830 & Restaurants have sterilization procedures for infection prevention. & \\
\hline & RPM6 & 0.823 & $\begin{array}{l}\text { Overall, restaurants have provided proper infection prevention measures to } \\
\text { avoid infection. }\end{array}$ & \\
\hline \multirow{5}{*}{$\mathrm{SN}$} & SN1 & 0.857 & My family think that it is fine to dine out & \multirow{5}{*}[14,60]{} \\
\hline & SN2 & 0.865 & My friends or colleagues think that it is fine to dine out & \\
\hline & SN3 & 0.641 & I dine out because people around me do so & \\
\hline & SN4 & 0.864 & Medical doctors or experts say that it is safe to dine out & \\
\hline & SN5 & 0.863 & The news says that it is safe to dine out & \\
\hline
\end{tabular}

Note: EJ = enjoyment; INT = intention of dining out; PHY = perceived physical risk; PSY = perceived psychological risk; RPM = restaurants' precautionary measures; $\mathrm{SN}=$ subjective norms.

After the pilot test, questionnaire links were sent to potential Chinese participants through WeChat (one of the most popular social media channels in China); meanwhile, the Korean data were mostly collected offline at restaurants located around the cities of Daejeon, Sejong, and Seoul. Before consumers participated in the survey, they were informed that their anonymity and privacy would be ensured and that data would be used for research purposes only. The data were collected during late October and early November, 2020, and a total of 514 questionnaires were collected. Of those 514 questionnaires, samples containing incomplete answers were deleted and a final sample of 508 cases (308 questionnaires from China and 200 questionnaires from Korea) was used in the analysis. Most participants were in their 30 s or 40 s, and around $90 \%$ of them were worried about getting infected when they went out. A sample profile can be found in Table 2. 


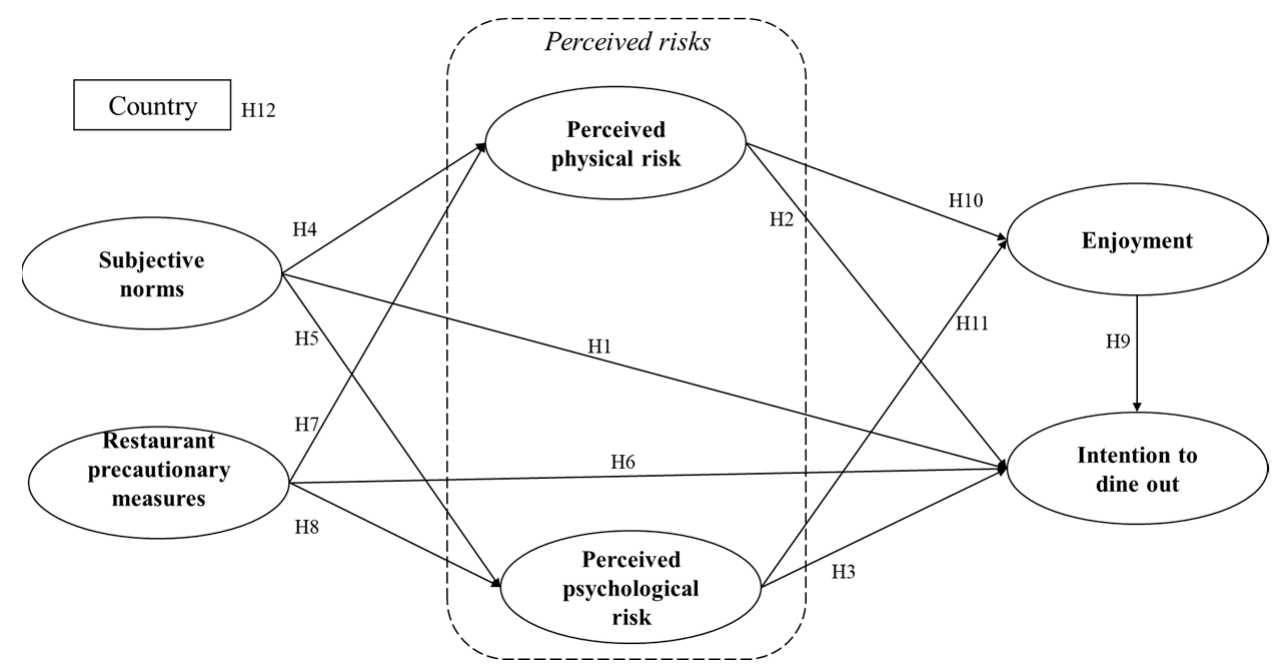

Figure 1. Conceptual model.

Table 2. Sample profile.

\begin{tabular}{|c|c|c|c|}
\hline \multicolumn{2}{|c|}{ Demographic Variables } & \multirow{3}{*}{$\begin{array}{c}\text { Frequency } \\
206 \\
302\end{array}$} & \multirow{3}{*}{$\begin{array}{c}\text { Percent } \\
40.6 \\
59.4\end{array}$} \\
\hline & Male & & \\
\hline Sex & Female & & \\
\hline \multirow{5}{*}{ Age } & 20 years old or under & 59 & 11.6 \\
\hline & 21-30 years old & 228 & 44.9 \\
\hline & $31-40$ years old & 157 & 30.9 \\
\hline & $41-50$ years old & 49 & 9.6 \\
\hline & Over 50 years old & 15 & 3.0 \\
\hline \multirow{5}{*}{ Education } & Below high school & 46 & 9.1 \\
\hline & High school/vocational school & 63 & 12.4 \\
\hline & Junior college & 91 & 17.9 \\
\hline & Undergraduate & 256 & 50.4 \\
\hline & Graduate or above & 52 & 10.2 \\
\hline \multirow{2}{*}{ Country } & China & 308 & 60.6 \\
\hline & Korea & 200 & 39.4 \\
\hline \multirow{5}{*}{ Frequency of dining out } & 1-2 times a week & 340 & 66.9 \\
\hline & 3-4 times a week & 112 & 22.0 \\
\hline & 5-6 times a week & 29 & 5.7 \\
\hline & Once a day & 11 & 2.2 \\
\hline & More than once a day & 16 & 3.1 \\
\hline \multirow{4}{*}{ Anxiety re. getting infected(if going out) } & Quite worried & 105 & 20.7 \\
\hline & Worried & 138 & 27.2 \\
\hline & A little worried & 195 & 38.4 \\
\hline & Not worried at all & 70 & 13.8 \\
\hline \multicolumn{2}{|l|}{ Total } & 508 & 100 \\
\hline
\end{tabular}

\subsection{Analysis Method}

We adopted the partial least squares structural equation modeling (PLS-SEM) method based on SmartPLS 3 software [61]. In accordance with Hair et al. (2016) [62], a 5000subsample method was used in the bootstrapping process. Due to the fact that PLS (partial least squares) is less limited by sample size and residual distribution [63], generally speaking, PLS can avoid inadmissible solutions and factor indeterminacy when it is adopted to analyze complicated relationships among different variables [64]. Nowadays, this method has become popular and has been applied frequently in many business-related 
studies [45,65]. As such, the partial least squares structural equation modeling (PLS-SEM) method was deemed to be suitable for this study.

\section{Analysis and Results}

\subsection{Measurement Model Results}

Measurement model results showed that overall the Cronbach's alpha of each variable was above 0.7 , indicating good internal consistency. According to Table 1, the factor loadings were all above the acceptable value of 0.5 [66], indicating adequate convergent validity. In terms of the AVE (average variance extracted) and CR (composite reliability), by following Bagozzi and Yi's (1988) [67] suggestions, the AVE and CR levels should be above 0.5 and 0.7 , respectively. Accordingly, the results also established proper construct reliability of the conceptual model. Furthermore, the square root of the AVE was greater than the interconstruct correlation, presenting good discriminant validity [68] (see Table 3).

Table 3. Fornell-Larcker criterion, reliability, and validity.

\begin{tabular}{|c|c|c|c|c|c|c|c|c|c|}
\hline & EJ & INT & SN & PHY & PSY & RPM & Cronbach's Alpha & C R & AVE \\
\hline Enjoyment & 0.790 & & & & & & 0.879 & 0.909 & 0.624 \\
\hline Intention of dining out & 0.635 & 0.868 & & & & & 0.918 & 0.939 & 0.754 \\
\hline Subjective norms & 0.371 & 0.531 & 0.823 & & & & 0.878 & 0.912 & 0.677 \\
\hline Perceived physical risk & -0.375 & -0.490 & -0.549 & 0.812 & & & 0.869 & 0.906 & 0.659 \\
\hline Perceived psychological risk & -0.409 & -0.549 & -0.398 & 0.639 & 0.849 & & 0.903 & 0.928 & 0.721 \\
\hline $\begin{array}{c}\text { Restaurant precautionary } \\
\text { measures }\end{array}$ & 0.187 & 0.294 & 0.421 & -0.379 & -0.185 & 0.77 & 0.857 & 0.895 & 0.592 \\
\hline
\end{tabular}

Note: diagonal line is square root of the AVE.

\subsection{Structural Model Results}

\subsubsection{Hypotheses Test Results}

The structural model results established that out of 11 hypotheses, three were not supported (see Table 4). We found that subjective norms positively influenced consumers' intention towards dining out $(\beta=0.238, p$-value $<0.05)$, supporting H1. Consumers' intentions towards dining out were directly affected by perceived psychological risk $(\beta=-0.266$, $p$-value $<0.05)$, accepting $\mathrm{H} 3$, but not perceived physical risk $(\beta=-0.007, p$-value $>0.05)$, rejecting H2. Subjective norms had very strong effects on both perceived physical risk $(\beta=-0.473, p$-value $<0.05)$ and perceived psychological risk $(\beta=-0.389, p$-value $<0.05)$, which supports $\mathrm{H} 4$ and $\mathrm{H} 5$. Furthermore, consumers' intentions towards dining out were not significantly affected by restaurants' precautionary measures $(\beta=0.063, p$-value $<0.05)$, rejecting H6. Restaurants' precautionary measures were statistically influential to perceived physical risk $(\beta=-0.180, p$-value $<0.05)$, supporting H7, while they did not significantly impact perceived psychological risk $(\beta=-0.021, p$-value $>0.05)$, rejecting H8. Enjoyment had positive implications for consumers' intentions towards dining out ( $\beta=0.424, p$-value $<0.05)$, accepting H9. The results also showed that both perceived physical risk $(\beta=-0.191, p$-value $<0.05)$ and perceived psychological risk $(\beta=-0.287$, $p$-value $<0.05$ ) played key roles in shaping consumers' enjoyment derived from dining out, which supports $\mathrm{H} 10$ and $\mathrm{H} 11$. 
Table 4. Hypotheses test.

\begin{tabular}{|c|c|c|c|c|c|}
\hline & Hypotheses & $\beta$ & Standard Deviation & $p$-Values & Result \\
\hline H1 & Subjective norms $\rightarrow$ intention & 0.238 & 0.046 & 0.000 & Supported \\
\hline $\mathrm{H} 2$ & Perceived physical risk $\rightarrow$ intention & -0.007 & 0.048 & 0.892 & Not Supported \\
\hline H3 & Perceived psychological risk $\rightarrow$ intention & -0.266 & 0.046 & 0.000 & Supported \\
\hline $\mathrm{H} 4$ & Subjective norms $\rightarrow$ perceived physical risk & -0.473 & 0.044 & 0.000 & Supported \\
\hline H5 & Subjective norms $\rightarrow$ perceived psychological risk & -0.389 & 0.048 & 0.000 & Supported \\
\hline H6 & Restaurants precautionary measures $\rightarrow$ intention & 0.063 & 0.038 & 0.102 & Not Supported \\
\hline $\mathrm{H} 7$ & Restaurants precautionary measures $\rightarrow$ Perceived physical risk & -0.180 & 0.042 & 0.000 & Supported \\
\hline $\mathrm{H} 8$ & $\begin{array}{c}\text { Restaurants precautionary measures } \rightarrow \text { Perceived } \\
\text { psychological risk }\end{array}$ & -0.021 & 0.049 & 0.665 & Not Supported \\
\hline H9 & Enjoyment $\rightarrow$ intention & 0.424 & 0.037 & 0.000 & Supported \\
\hline H10 & Perceived physical risk $\rightarrow$ enjoyment & -0.191 & 0.057 & 0.001 & Supported \\
\hline H11 & Perceived psychological risk $\rightarrow$ enjoyment & -0.287 & 0.062 & 0.000 & Supported \\
\hline
\end{tabular}

\subsubsection{Country Moderation Test Results}

Parametric test results suggested that out of 11 paths, H4, H5, H10, and H11 showed some differences between China and Korea regarding food consumption (see Table 5). The results indicated that the subjective norms seemed to have stronger effects on Chinese consumers' perceived physical risk $(\beta \mathrm{CN}=-0.508, \beta \mathrm{KR}=-0.295, p$ path-diff $<0.05)$ and perceived psychological risks $(\beta \mathrm{CN}=-0.513, \beta \mathrm{KR}=-0.081, p$ path-diff $<0.05)$ than Koreans. At the same time, Chinese consumers' enjoyments gained from dining out were more likely to be influenced by perceived physical risk $(\beta \mathrm{CN}=-0.275, \beta \mathrm{KR}=-0.051$, $p$ path-diff $<0.05)$ and perceived psychological risk $(\beta \mathrm{CN}=-0.396, \beta \mathrm{KR}=-0.165$, $p$ path-diff $<0.05)$. Thus, H12 was partially supported.

Table 5. Multigroup analysis parametric test.

\begin{tabular}{|c|c|c|c|c|}
\hline \multirow{2}{*}{\multicolumn{2}{|c|}{ Hypotheses }} & $\beta$ & $\beta$ & $p$-Value \\
\hline & & $(\mathrm{CN})$ & $(\mathrm{KR})$ & (CN vs. $\mathrm{KR})$ \\
\hline $\mathrm{H} 1$ & Subjective norms $\rightarrow$ intention & 0.186 & 0.273 & 0.272 \\
\hline $\mathrm{H} 2$ & Physical risk $\rightarrow$ intention & -0.080 & 0.074 & 0.098 \\
\hline H3 & Perceived psychological risk $\rightarrow$ intention & -0.272 & -0.29 & 0.834 \\
\hline $\mathrm{H} 4$ & Subjective norms $\rightarrow$ physical risk & -0.508 & -0.295 & $0.035 *$ \\
\hline H5 & Subjective norms $\rightarrow$ perceived psychological risk & -0.513 & -0.081 & $0.000 *$ \\
\hline H6 & Restaurants precautionary measures $\rightarrow$ intention & 0.103 & 0.124 & 0.771 \\
\hline $\mathrm{H} 7$ & Restaurants precautionary measures $\rightarrow$ Perceived physical risk & -0.091 & -0.081 & 0.915 \\
\hline $\mathrm{H} 8$ & Restaurants precautionary measures $\rightarrow$ Perceived psychological risk & -0.143 & 0.070 & 0.071 \\
\hline H9 & Enjoyment $\rightarrow$ intention & 0.429 & 0.346 & 0.263 \\
\hline H10 & Perceived physical risk $\rightarrow$ enjoyment & -0.275 & -0.051 & $0.042 *$ \\
\hline H11 & Perceived psychological risk $\rightarrow$ enjoyment & -0.396 & -0.165 & $0.041 *$ \\
\hline
\end{tabular}

Note: $\mathrm{CN}=$ China; $\mathrm{KR}=$ Korea; ${ }^{*} p$ value $<0.05$.

\section{Discussion and Conclusion}

\subsection{Theoretical Implications}

In this study, we intended to identify the factors that can significantly impact upon people's food consumption behaviors of dining out under the new normal context. The results revealed that subjective norms (opinions of reference groups and people around them) have a positive effect on consumers' behavioral intentions towards dining out, which aligns with Nguyen et al.'s (2020) [14] study on consumers' intentions to purchase functional foods in Vietnam. We confirmed that opinions of reference groups are critically important to consumers' food consumption decisions. Both Chinese and Korean people are significantly influenced by norms or social patterns within their societies. According to the results, subjective norms also showed strong effects on consumers' perceived physical risk and psychological risk. This could be a new finding to the current knowledge, because in this study we have verified that opinions of a reference group are decisive to people's 
risk perceptions regarding dining out. Consumers tend to perceive less risks if others suggest that dining-out behavior is safe. Their decisions can greatly rely on suggestions from friends, family, and experts.

We also found that perceived psychological risk has negative effects on consumers' intention. These findings were similar to Gupta et al.'s (2018) [56] study on street food consumption, which showed that perceived risk negatively shaped consumers' decisionmaking processes. Others studies have also stated that perceived psychological risks can shape individuals' food consumption motivation and consequently affect their behavioral intentions $[37,51]$. But perceived physical risk showed no effects on consumers' intention, which ran against our expectations. However, many respondents did indicate that psychologically, they had certain concerns about dining out. In this study, almost $90 \%$ of participants suggested that they were somehow worried about coronavirus infection when they dine out. Even in both of these countries, where they all have relatively low infection rates with desire to adapt to the so-called new normal, people still live under the shadow of coronavirus, perceiving strong psychological risks of infection, which indicates that the damage caused by the pandemic may last longer than we expected. It may be difficult for consumers to actually return to their normal lives due to the uncertainty caused by the virus, and their fears could impact upon their consumption behaviors and, consequently, hinder the recovery of the economy. Therefore, providing further understanding of their behavioral pattern changes is vital in this study.

Moreover, the results indicated that precautionary procedures within restaurants have no direct implications on consumers' intention towards dining out, but such measures may help to lower consumers' perceived risks, particularly, physical risk. It means certain infection prevention measures (such as regular sterilization procedures, or offering separated dining spaces, hand sanitizer, and contactless payment) are necessarily important. Consumers are less exposed to risks of coronavirus infection with adequate disinfection measures and social distancing. As a result, they would feel safer and be more willing to eat out if restaurants have taken such precautionary measures. Thus, in this study, precautionary measures have been confirmed to be an influential factor in reducing perceived physical risk, and restaurants should continuously take disinfection measures and keep certain social distancing rules to ensure the safety of consumers.

In this study, we also generated some other findings. Consistent with previous studies [43], the results also showed that consumers' dining out intentions may be largely shaped by the enjoyment factor, because dining out brings consumers some fun and food consumption involving positive interaction with friends and families may provide a more enjoyable experience; as a result, it may lead to a positive attitude and continuous purchasing behaviors [45]. This finding proved that enjoyment is still an indispensable variable in food consumption decision-making among Chinese and Korean people in the new normal' context. But interestingly, we found that such enjoyment is negatively affected by perceived physical risk and perceived psychological risk. If people perceive high risks of infection when they dine out, this could comparatively reduce their pleasure and enjoyment. In other words, they may not be able to fully enjoy the happiness of dining with friends or families under the shadow of the pandemic. Therefore, this study also provided new evidence demonstrating the correlations between perceived physical/psychological risk and enjoyment in food consumption activities. When people have fears or concerns and perceived health risks about getting infected, the dining out experience is inclined to be less enjoyable.

Finally, we found some differences between China and Korea regarding dining out. Compared to Chinese consumers, Koreans' perceived physical/psychological risks are less affected by subjective norms. This can be explained by the following reasons: Both Korea and China have highly collectivist culture, where people tend to belong to 'in groups' [12], and their societies are largely guided by norms or obligations [1]. However, subjective norms may play a more significant role in countries with less newly reported cases. If the overall environment within a country is relatively safe and it has had less cases reported 
recently, the opinions of a reference group might tend to be more convincible. So, when the reference group suggests that dining out is safe, consumers are more likely to believe it. Before we carried out our survey, number of infection cases were different in these two countries. From 1 October to 12 October, newly reported cases in China were all imported cases (less than 30 per day) without any local transmission [69]. During October and November, local infection cases only reported in a few cities in China such as Qingdao, but the overall environment was quite safe, with most of the cities reporting no cases. On the contrary, in Korea, although the infection rate was low, local new infection cases were being reported continuously across cities and on 23 October, 155 new cases of Covid-19 were reported (including 138 local infection cases), which was the highest number of new infection cases in over a month [70]. As local infections continued to spread across Korea, even if reference groups indicated that it was safe to eat out, their opinions can be less convincible and influential to Korean consumers, which may not have huge effects on consumers' risk perceptions. Furthermore, based on the country comparison results, we found that overall, Chinese consumers tended to be more sensitive to risks than Koreans with higher path coefficients in almost every risk-related hypothesis. This also can probably explain why Chinese consumers' risk perceptions are more strongly corelated with other factors. Thus, external factors like subjective norms could influence their perceived risks more powerfully.

Another interesting finding of this study was that for Chinese consumers, perceived physical/psychological risk tended to carry more negative implications on their enjoyments of dining out than Koreans. With continuous and increasing numbers of local infections reported in Korea, we thought that Korean consumers might be more anxious and their enjoyments of dining out would be more affected by perceived physical/psychological risks, but the results turned out to reflect the opposite notion. One of the reasons for this is that lots of people in China have experienced a long period of lockdown [71], but there have been no major lockdowns announced in Korea during the pandemic so far [70]. Lockdowns for weeks created certain issues for Chinese people's mental health [72]. In particular, people in China who experienced such lockdowns may suffer from long-term psychological problems. It is understandable that with the stronger fear of suddenly returning to extremely strict lockdowns and serious cluster infections, many Chinese people may worry that under the eased control measures, the virus could restart easily or even be reintroduced into China from other regions such as Europe and the United States, which are now suffering from their first, second, or third wave of COVID-19. Meanwhile, suspicions about media coverage and misinformation relating to COVID-19 may also cause increasing incidence of depression and stress among Chinese people [73]. This may increase their risk perceptions of physical harm from dining out. Thus, even with the comparatively low infection rate being reported, Chinese consumers may experience more negative emotions and perceive more physical risks of infection, which may reduce their enjoyments more greatly when they are dining out.

The above findings can significantly contribute to the theoretical basis for understanding consumers' food consumption and dining-out behaviors under the new normal context. Factors such as subjective norms, perceived physical and psychological risks, enjoyment, and restaurant precautionary measures are all of paramount importance in the decisionmaking process for dining out. More importantly, the differences between countries that we presented in this study will deepen the understanding of social and cultural influences on consumers' dining-out behaviors.

\subsection{Managerial Implications}

Besides theoretical implications, this study also can provide some insight for business practices. According to these results, enjoyment as an indispensable variable has strong implications for consumers' behavioral intentions, followed by perceived psychological risk and subjective norms. We also found that subjective norms and restaurant precautionary measures are significantly associated with perceived physical/psychological risk. 
Therefore, based on these key factors, managers in the restaurant industry should consider the following suggestions to deal with declining sales during the pandemic.

(1) Restaurant managers should try to provide more services that can bring joy to consumers and, in turn, this can lead to positive attitude and increase the number of consumers. For example, in areas with less infected cases, providing customized service for family / friend dinner gatherings (offering more diverse menu, birthday party event service, etc.) or doing promotions more frequently (giving coupons, gifts etc.). It is also vital for restaurants to have outdoor dining space. Restaurants can build outdoor dining space under certain limitations on occupancy and use outdoor electric heaters to keep a comfortable dining environment during the cold winter, through which consumers may feel safer and comfortable, and such measures can allow them to enjoy dining with less risks of getting infected than indoor dining [74].

(2) With the virus continuing to spread worldwide, people may perceive more psychological risk in eating out. As such, it could be useful if restaurants provide information about whether daily disinfection measures are being carried out adequately, and they should inform consumers of such information by posting notices on the restaurant websites or via printed notices on the menu, table, front doors, or check-out counters. This may serve to decrease the negative perceptions of the psychological risks of dining out, such as fear, stress, or other negative infection-related emotions. In addition, because online-based food delivery services could be more convenient and safer than dining out to some consumers [75], an easy-to-use delivery system can offer an efficient channel for exchanging information and products during the pandemic [76]. Therefore, restaurants could also focus more on online ordering and delivering in areas with high infection rates, which might reduce consumers' safety concerns and be an alternative to dining out.

(3) As consumers' risk perceptions and their behaviors are greatly influenced by reference groups, managers may offer coupons or discounts to individuals who recommend their restaurant to others on social media or leave five-star reviews on restaurant websites. Moreover, because consumers may have concerns about the safety of dining out, restaurants might work with the government to build an app that provides a recommendation list of restaurants that follow sanitary and distancing guidelines [77]. On such apps, restaurants with high scores for safety/precautionary measures can be recommended to more people. Consequently, this can attract more consumers and help with sales. Particularly, for Chinese consumers, external opinions of families/friends and experts can be extremely crucial to reduce their risk perceptions, which means that Chinese people might highly rely on external information sources. Restaurants in China may try to keep information more transparent and detailed, for example, providing more up-to-date information about food sources, daily disinfection measures, and the health status of restaurant employees on the said apps, through which they may reduce consumers' risk perceptions more efficiently and increase Chinese consumers' enjoyment of dining out.

(4) Moreover, as restaurant precautionary measures can reduce consumers' perceived physical risk, restaurants should provide more measures to reduce the possibilities of infection. Recently, in order to avoid close contact and minimize the risks of coronavirus infection, contactless payment methods like facial recognition payment have been increasingly popular [78]. Besides providing more contactless payment services, restaurants should also regularly carry out COVID-19 disinfection, offer hand sanitizer/divided dining spaces, or use robots to serve, which in turn, may diminish the risk perceptions of consumers and enable them to enjoy more when they are dining out.

\subsection{Conclusions and Limitations}

The results of this study revealed that subjective norms, perceived physical/ psychological risks, enjoyment, and restaurant precautionary measures are vital factors 
that can affect consumers' dining-out behaviors. Even though it has been almost a year since the start of the outbreak, people still perceive huge psychological risks and pay a significant amount of attention to precautionary measures when they are dining out. Currently, the virus is continuously spreading all over the world, and vaccines are only available for a limited number people in countries like the UK, the US, etc., but living with the virus still continues as the new normal for many parts of the world. Moreover, with lots of uncertainties caused by the mutations of coronavirus, and suspicions on the long-term immunity provided by the vaccines, many people may still be skeptical about the vaccination. People still have great concerns about getting infected when they are outside, and their consumption patterns are expected to be continuously affected by such negative emotions in the long term. It is very important that restaurant owners or managers should find ways to adapt their business models to such changes in consumers' behavior in order to sustain or recover during and after the pandemic.

In this study, we have presented some meaningful findings and practical suggestions that can enrich the theoretical basis for understanding people's dining-out behaviors across countries, and also offer insight to enable managers to adapt their business strategies as required under the concept of the new normal. More importantly, we also believe the significance of this study will not fade away even after the pandemic. The COVID-19 pandemic is one of the worst pandemics in the history, but due to the frequent human interaction with the natural world, it is more likely that there will be more future outbreaks of other infectious diseases [2]. Thus, it is vital to understand how the COVID-19 pandemic has affected patterns of consumer behavior in a more comprehensive way, which in turn, may offer managers more efficient ways to meet consumers' needs and get them prepared for any other similar situations in the future.

However, unavoidably, the study also suffers from certain limitations. The limitations and future research directions are presented as follows: Firstly, even though more than 500 cases were used in the analysis, it would be beneficial to include more participants from other countries, and doing so could generate new findings. Due to differences in cultures, coronavirus infection rates, and so forth, country comparison between European countries and other Asian countries could be interesting. Secondly, due to limited previous studies that had systematically investigated how people's dining-out behaviors were affected by the pandemic under the new normal concept in China or Korea, it may be hard to identify very strong theoretical grounding for all of the findings. To generate more interesting insight, future studies could carry on similar topics or focus on other industries. Thirdly, most participants were under 40 years of age, so it could be better to include a greater range of respondents from more varied age groups and moderation effects of demographic characteristics (age, gender etc.) could be tested in future studies. Finally, other factors such as perceived benefits and public health intervention policies that can influence consumption activities may also be considered in further research on related topics.

Author Contributions: Conceptualization, Y.Z., H.C.M., and S.O.; methodology, Y.Z.; formal analysis, Y.Z.; investigation, Y.Z. and S.O; writing-original draft preparation, Y.Z.; writing-review and editing, Y.Z. and H.C.M.; supervision, H.C.M.; project administration, H.C.M.; funding acquisition, H.C.M. All authors have read and agreed to the published version of the manuscript.

Funding: This work was supported by the Ministry of Education of the Republic of Korea and the National Research Foundation of Korea, grant number NRF-2019K2A9A2A0602441012.

Institutional Review Board Statement: The study was conducted according to the research guidelines approved by Ethics Committee of Chungnam National University.

Informed Consent Statement: Informed consent was obtained.

Data Availability Statement: Not available to the public. The data presented in this study are available only on reasonable request from the corresponding author due to privacy of research participants.

Conflicts of Interest: The authors declare no conflict of interest. 


\section{References}

1. Wen, J.; Kozak, M.; Yang, S.; Liu, F. COVID-19: Potential effects on Chinese citizens' lifestyle and travel. Tour. Rev. 2020, in press. [CrossRef]

2. BBC News. Coronavirus: This Is Not the Last Pandemic. 2020. Available online: https://www.bbc.com/news/scienceenvironment-52775386 (accessed on 7 December 2020).

3. Bae, S.Y.; Chang, P.-J. The effect of coronavirus disease-19 (COVID-19) risk perception on behavioural intention towards 'untact'tourism in South Korea during the first wave of the pandemic (March 2020). Curr. Issues Tour. 2020, 1-19. [CrossRef]

4. Xie, X.; Huang, L.; Li, J.J.; Zhu, H. Generational Differences in Perceptions of Food Health/Risk and Attitudes toward Organic Food and Game Meat: The Case of the COVID-19 Crisis in China. Int. J. Environ. Res. Public Health 2020, 17, 3148. [CrossRef]

5. Laguna, L.; Fiszman, S.; Puerta, P.; Chaya, C.; Tárrega, A. The impact of COVID-19 lockdown on food priorities. Results from a preliminary study using social media and an online survey with Spanish consumers. Food Qual. Prefer. 2020, 86, 104028. [CrossRef] [PubMed]

6. Kim, J.; Kim, J.; Lee, S.K.; Tang, L.R. Effects of epidemic disease outbreaks on financial performance of restaurants: Event study method approach. J. Hosp. Tour. Manag. 2020, 43, 32-41. [CrossRef]

7. Korea.Net. New Normal in Daily Life for Korea, World. 2020. Available online: http://www.korea.net/NewsFocus/ HonoraryReporters / view?articleId=186054\&pageIndex=1 (accessed on 11 November 2020).

8. YONHAP NEWS. Korea Eases Social Distancing to Lowest Level Amid Coronavirus Downward Trend. 2020. Available online: https: / / en.yna.co.kr/view / AEN20201011002353315 (accessed on 10 November 2020).

9. China Briefing. Taking Advantage of China's New Normal. 2020. Available online: https://www.china-briefing.com/news/ taking-advantage-of-chinas-new-normal (accessed on 11 November 2020).

10. GOAL. Adjusting to Korean Life-Cultural Differences When Dining Out in Korea. 2016. Available online: https://www.goal.or. $\mathrm{kr}$ /content/adjusting-korean-life-cultural-differences-when-dining-out-korea (accessed on 10 January 2021).

11. Rizou, M.; Galanakis, I.M.; Aldawoud, T.M.; Galanakis, C.M. Safety of foods, food supply chain and environment within the COVID-19 pandemic. Trends Food Sci. Technol. 2020, 102, 293-299. [CrossRef]

12. Hofstede Insights. Country Comparison. 2020. Available online: https://www.hofstede-insights.com/country-comparison/ china, south-korea (accessed on 10 January 2021).

13. Ravlin, E.C.; Liao, Y.; Morrell, D.L.; Au, K.; Thomas, D.C. Collectivist orientation and the psychological contract: Mediating effects of creditor exchange ideology. J. Int. Bus. Stud. 2012, 43, 772-782. [CrossRef]

14. Nguyen, N.; Nguyen, H.V.; Nguyen, P.T.; Tran, V.T.; Nguyen, H.N.; Nguyen TM, N.; Cao, T.K.; Nguyen, T.H. Some Key Factors Affecting Consumers' Intentions to Purchase Functional Foods: A Case Study of Functional Yogurts in Vietnam. Foods 2020, 9, 24. [CrossRef]

15. Marty, L.; de Lauzon-Guillain, B.; Labesse, M.; Nicklaus, S. Food choice motives and the nutritional quality of diet during the COVID-19 lockdown in France. Appetite 2020, 157, 105005. [CrossRef]

16. Poelman, M.P.; Gillebaart, M.; Schlinkert, C.; Dijkstra, S.C.; Derksen, E.; Mensink, F.; de Vet, E. Eating behavior and food purchases during the COVID-19 lockdown: A cross-sectional study among adults in the Netherlands. Appetite 2020, 157, 105002. [CrossRef] [PubMed]

17. Scarmozzino, F.; Visioli, F. Covid-19 and the Subsequent Lockdown Modified Dietary Habits of Almost Half the Population in an Italian Sample. Foods 2020, 9, 675. [CrossRef]

18. Matiza, T. Post-COVID-19 crisis travel behaviour: Towards mitigating the effects of perceived risk. J. Tour. Futures 2020. [CrossRef]

19. Fishbein, M.; Ajzen, I. Belief, Attitude, Intention, and Behavior: An Introduction to Theory and Research; Elsevier Science Publishing Co.,Inc.: New York, NY, USA, 1977.

20. Hale, J.L.; Householder, B.J.; Greene, K.L. The theory of reasoned action. In The Persuasion Handbook: Developments in Theory and Practice; Sage Publications: London, UK, 2002; Volume 14, pp. 259-286.

21. Lada, S.; Tanakinjal, G.H.; Amin, H. Predicting intention to choose halal products using theory of reasoned action. Int. J. Islamic Middle East. Financ. Manag. 2009, 2, 66-76. [CrossRef]

22. Hussain, I.; Rahman, S.U.; Zaheer, A.; Saleem, S. Integrating factors influencing consumers' halal products purchase: Application of theory of reasoned action. J. Int. Food Agribus. Mark. 2016, 28, 35-58. [CrossRef]

23. Shepherd, R.; Sparks, P.; Bellier, S.; Raats, M. Attitudes and choice of flavoured milks: Extensions of Fishbein and Ajzen's theory of reasoned action. Food Qual. Prefer. 1991, 3, 157-164. [CrossRef]

24. Chiu, C.M.; Chang, C.C.; Cheng, H.L.; Fang, Y.H. Determinants of customer repurchase intention in online shopping. Online Inf. Rev. 2009, 33, 761-784. [CrossRef]

25. Çelik, H. Influence of social norms, perceived playfulness and online shopping anxiety on customers' adoption of online retail shopping: An empirical study in the Turkish context. Int. J. Retail Distrib. Manag. 2011, 39, 390-413. [CrossRef]

26. Hao Suan Samuel, L.; Balaji, M.; Kok Wei, K. An investigation of online shopping experience on trust and behavioral intentions. J. Internet Commer. 2015, 14, 233-254. [CrossRef]

27. Rogers, E.M. Diffusion of Innovations. In Simon and Schuster; The Free Press: New York, NY, USA, 2010.

28. Ajzen, I. The theory of planned behavior. Organ. Behav. Hum. Decis. Process. 1991, 50, 179-211. [CrossRef]

29. Bhattacherjee, A. Acceptance of e-commerce services: The case of electronic brokerages. IEEE Trans. Syst. Man Cybern. Part A Syst. Hum. 2000, 30, 411-420. [CrossRef] 
30. Bauer, R.A. Consumer Behavior as Risk Taking; Routledge: Chicago, IL, USA, 1960; pp. 384-398.

31. Mowen, J.C.; Minor, M. Consumer Behavior; Prentice Hall: Upper Saddle River, NJ, USA, 1998.

32. Reisinger, Y.; Mavondo, F. Travel anxiety and intentions to travel internationally: Implications of travel risk perception. J. Travel Res. 2005, 43, 212-225. [CrossRef]

33. Mitchell, V.W.; Boustani, P. Consumer risk perceptions in the breakfast cereal market. Br. Food J. 1992, 94, 17-26. [CrossRef]

34. Novelli, M.; Burgess, L.G.; Jones, A.; Ritchie, B.W. ‘No Ebola ... still doomed'-The Ebola-induced tourism crisis. Ann. Tour. Res. 2018, 70, 76-87. [CrossRef]

35. Lerner, J.S.; Keltner, D. Beyond valence: Toward a model of emotion-specific influences on judgement and choice. Cogn. Emot. 2000, 14, 473-493. [CrossRef]

36. Stefani, G.; Cavicchi, A.; Romano, D.; Lobb, A.E. Determinants of intention to purchase chicken in Italy: The role of consumer risk perception and trust in different information sources. Agribus. Int. J. 2008, 24, 523-537. [CrossRef]

37. Floyd, M.F.; Gibson, H.; Pennington-Gray, L.; Thapa, B. The effect of risk perceptions on intentions to travel in the aftermath of September 11, 2001. J. Travel Tour. Mark. 2004, 15, 19-38. [CrossRef]

38. Wu, T.; Perrings, C.; Kinzig, A.; Collins, J.P.; Minteer, B.A.; Daszak, P. Economic growth, urbanization, globalization, and the risks of emerging infectious diseases in China: A review. Ambio 2017, 46, 18-29. [CrossRef] [PubMed]

39. Chen, H.; Qian, W.; Wen, Q. The impact of the COVID-19 pandemic on consumption: Learning from high frequency transaction data. SSRN 2020. [CrossRef]

40. Morrow Jr, J.; Hansen, M.H.; Pearson, A.W. The cognitive and affective antecedents of general trust within cooperative organizations. J. Manag. Issues 2004, 16, 48-64.

41. Shahbaz, M.; Bilal, M.; Moiz, A.; Zubair, S.; Iqbal, H.M. Food Safety and COVID-19: Precautionary Measures to Limit the Spread of Coronavirus at Food Service and Retail Sector. J. Pure Appl. Microbiol. 2020, 14, 6203. [CrossRef]

42. Pressman, P.; Naidu, A.S.; Clemens, R. COVID-19 and food safety: Risk management and future considerations. Nutr. Today 2020, 55, 125-128. [CrossRef]

43. Park, C. Efficient or enjoyable? Consumer values of eating-out and fast food restaurant consumption in Korea. Int. J. Hosp. Manag. 2004, 23, 87-94. [CrossRef]

44. Finkelstein, J. Dining Out: A Sociology of Modern Manners; Polity Press: Cambridge, UK, 1989.

45. Zhong, Y.; Moon, H.C. What Drives Customer Satisfaction, Loyalty, and Happiness in Fast-Food Restaurants in China? Perceived Price, Service Quality, Food Quality, Physical Environment Quality, and the Moderating Role of Gender. Foods 2020, 9, 460. [CrossRef]

46. Konuk, F.A. The influence of perceived food quality, price fairness, perceived value and satisfaction on customers' revisit and word-of-mouth intentions towards organic food restaurants. J. Retail. Consum. Serv. 2019, 50, 103-110. [CrossRef]

47. Rouibah, K.; Lowry, P.B.; Hwang, Y. The effects of perceived enjoyment and perceived risks on trust formation and intentions to use online payment systems: New perspectives from an Arab country. Electron. Commer. Res. Appl. 2016, 19, 33-43. [CrossRef]

48. Ha, Y.; Im, H. Determinants of mobile coupon service adoption: Assessment of gender difference. Int. J. Retail Distrib. Manag. 2014, 42, 441-459. [CrossRef]

49. Sullivan, Y.W.; Kim, D.J. Assessing the effects of consumers' product evaluations and trust on repurchase intention in e-commerce environments. Int. J. Inf. Manag. 2018, 39, 199-219. [CrossRef]

50. Hussain, S.; Ahmed, W.; Jafar RM, S.; Rabnawaz, A.; Jianzhou, Y. eWOM source credibility, perceived risk and food product customer's information adoption. Comput. Hum. Behav. 2017, 66, 96-102. [CrossRef]

51. Han, H.; Yu, J.; Kim, W. An electric airplane: Assessing the effect of travelers' perceived risk, attitude, and new product knowledge. J. Air Transp. Manag. 2019, 78, 33-42. [CrossRef]

52. Cheng, V.C.; Wong, S.-C.; Chuang, V.W.; So, S.Y.; Chen, J.H.; Sridhar, S.; To, K.K.; Chan, J.F.; Hung, I.F.; Ho, P.-L. The role of community-wide wearing of face mask for control of coronavirus disease 2019 (COVID-19) epidemic due to SARS-CoV-2. J. Infect. 2020, 81, 107-114. [CrossRef] [PubMed]

53. National Health Commission of the People's Republic of China. China CDC Warns against Cross-Border Travel in National Day Holiday. 2020. Available online: http:/ / en.nhc.gov.cn/2020-09/24/c_81740.htm (accessed on 11 November 2020).

54. YONHAP NEWS. Korea's New Coronavirus Cases Bounce Back to Triple Digits. 2020. Available online: https://en.yna.co.kr/ view / AEN20201015002652320 (accessed on 10 November 2020).

55. Venkatesh, V.; Thong, J.Y.; Xu, X. Consumer acceptance and use of information technology: Extending the unified theory of acceptance and use of technology. MIS Q. 2012, 36, 157-178. [CrossRef]

56. Gupta, V.; Khanna, K.; Gupta, R.K. A study on the street food dimensions and its effects on consumer attitude and behavioural intentions. Tour. Rev. 2018, 73, 374-388. [CrossRef]

57. Domina, T.; Lee, S.-E.; MacGillivray, M. Understanding factors affecting consumer intention to shop in a virtual world. J. Retail. Consum. Serv. 2012, 19, 613-620. [CrossRef]

58. Wang, E.S.-T. Effect of food service-brand equity on consumer-perceived food value, physical risk, and brand preference. Br. Food J. 2015, 117, 553-564. [CrossRef]

59. Zhu, H.; Deng, F. How to Influence Rural Tourism Intention by Risk Knowledge during COVID-19 Containment in China: Mediating Role of Risk Perception and Attitude. Int. J. Environ. Res. Public Health 2020, 17, 3514. [CrossRef] [PubMed] 
60. Okumus, B.; Bilgihan, A. Proposing a model to test smartphone users' intention to use smart applications when ordering food in restaurants. J. Hosp. Tour. Technol. 2014, 5, 31-49. [CrossRef]

61. Ringle, C.M.; Wende, S.; Becker, J.-M.S. SmartPLS 3; SmartPLS GmbH: Bönningstedt, Germany, 2015.

62. Hair, J.F., Jr.; Hult, G.T.M.; Ringle, C.; Sarstedt, M. A Primer on Partial Least Squares Structural Equation Modeling (PLS-SEM); Sage publications: London, UK, 2016.

63. Chin, W.W.; Marcolin, B.L.; Newsted, P.R. A partial least squares latent variable modeling approach for measuring interaction effects: Results from a Monte Carlo simulation study and an electronic-mail emotion/adoption study. Inf. Syst. Res. 2003, 14, 189-217. [CrossRef]

64. Fornell, C.; Bookstein, F.L. Two structural equation models: LISREL and PLS applied to consumer exit-voice theory. J. Mark. Res. 1982, 19, 440-452. [CrossRef]

65. Müller, J.M.; Kiel, D.; Voigt, K.-I. What drives the implementation of Industry 4.0? The role of opportunities and challenges in the context of sustainability. Sustainability 2018, 10, 247. [CrossRef]

66. Thompson, R.; Barclay, D.; Higgins, C.A. The partial least squares approach to causal modeling: Personal computer adoption and use as an illustration. Technol. Stud. Spec. Issue Res. Methodol. 1995, 2, 284-324.

67. Bagozzi, R.P.; Yi, Y. On the evaluation of structural equation models. J. Acad. Mark. Sci. 1988, 16, 74-94. [CrossRef]

68. Fornell, C.; Larcker, D.F. Evaluating structural equation models with unobservable variables and measurement error. J. Mark. Res. 1981, 18, 39-50. [CrossRef]

69. China Daily. Latest on the COVID Outbreak. 2020. Available online: http://global.chinadaily.com.cn/a/202009/29/WS5f2 4 addba31083481725d877.html (accessed on 15 November 2020).

70. Central Disaster Management Headquarters. Coronavirus Disease-19. 2020. Available online: http://ncov.mohw.go.kr/en/ (accessed on 15 November 2020).

71. Cyranoski, D. What China's coronavirus response can teach the rest of the world. Nature 2020, 579, 479-480. [CrossRef] [PubMed]

72. Baculinao, E.; Shi, A.; Wu, V.; Talmazan, Y. Lockdowns to Curb Coronavirus Epidemic Lead to A Rise in Mental Health Issues. In NBC News. Available online: https:/ / www.nbcnews.com/news/world/lockdowns-curb-coronavirus (accessed on 15 November 2020).

73. Gan, Y.; Ma, J.; Wu, J.; Chen, Y.; Zhu, H.; Hall, B.J. Immediate and delayed psychological effects of province-wide lockdown and personal quarantine during the COVID-19 outbreak in China. Psychol. Med. 2020, 1-12. [CrossRef]

74. Reuters. 'It worked': In New York City, Pandemic-Inspired Outdoor Dining to Become Permanent. 2020. Available online: https:/ / www.reuters.com/article/us-health-coronavirus-new-york-restauran-idUSKCN26G2Z4 (accessed on 16 November 2020).

75. Mehrolia, S.; Alagarsamy, S.; Solaikutty, V.M. Customers response to online food delivery services during COVID-19 outbreak using binary logistic regression. Int. J. Consum. Stud. 2020, 1-12. [CrossRef]

76. Oh, S.; Moon, H.C.; Zhong, Y. Contingency Management and Supply Chain Performance in Korea: A COVID-19 Pandemic Approach. Sustainability 2020, 12, 9823. [CrossRef]

77. The Korea Herald. S. Korea to Provide Open Data on 'Virus-Safe' Restaurants. 2020. Available online: http:/ / www.koreaherald. com/view.php?ud=20200804000362 (accessed on 12 November 2020).

78. Zhong, Y.; Oh, S.; Moon, H.C. Service transformation under industry 4.0: Investigating acceptance of facial recognition payment through an extended technology acceptance model. Technol. Soc. 2021, 64, 101515. [CrossRef] 